\title{
The Effect of Benefits Counseling on Increasing Knowledge of Social Security Work Rules and Work Incentives
}

\author{
Claudia Pettit ${ }^{1}$ a \\ ${ }^{1}$ Michigan Rehabilitation Services \\ Keywords: benefits counseling, knowledge, vocational rehabilitation \\ https://doi.org/10.52017/001c.28184
}

\section{Rehabilitation Counselors and Educators Journal}

Vol. 10, Issue 2, 2021

\begin{abstract}
Work incentives benefits counseling is a service designed to help participants better understand the interplay between earnings and benefits and reduce fear by navigating the various work incentive options as they prepare for and enter or re-enter the workforce. Michigan Rehabilitation Services (MRS) evaluated participant changes in knowledge specific to Social Security Administration work rules and work incentives available through various public programs. Findings indicated that participant knowledge in these areas generally increases following the receipt of benefits counseling services.
\end{abstract}

\section{Background and Purpose}

Supplemental Security Income (SSI) and Social Security Disability Insurance (SSDI), the two primary financial assistance programs administered by the Social Security Administration for individuals with disabilities, have experienced substantial growth in recent decades. These programs include an array of incentives to support work activity; however, the employment rate of individuals with disabilities participating remains relatively low due to a variety of reasons, including fear of losing access to cash and health insurance benefits (Hartman et al., 2015; Mann et al., 2015). Work incentives benefits counseling is a service designed to help participants better understand the interplay between earnings and benefits and reduce fear by navigating the various work incentive options as they prepare for and enter or re-enter the workforce. Consistent with this approach, a growing body of evidence indicates that youth and adult Vocational Rehabilitation (VR) consumers who engage in this service have significantly higher work activity than those who do not (Kregel, 2012; Schlegelmilch et al., 2019; Wilhelm \& McCormick, 2013).

Michigan Rehabilitation Services (MRS) implemented a pilot to offer benefits counseling to VR customers receiving Social Security benefits in five MRS offices delivered by three Disability Networks and/or Centers for Independent Living. Benefits Counseling (BC) services were provided by trained Community Partner Work Incentives Coordinators (CPWICs) to increase participant knowledge of Social Security work incentives and other community resources. The purpose of the study was to evaluate the effectiveness of benefits counseling provided to MRS customers and the research questions included:

1. Does benefits counseling improve a customer's knowledge of Social Security work rules?

2. Does benefits counseling improve a customer's knowledge of work incentives?

3. Does knowledge of work incentives relate to their intention to use work incentives?

\section{Methods}

A total of 82 Social Security recipients participated in the study from July 1, 2019 through February 29, 2020. Twentyfour (24) participants received Supplemental Security Income (SSI) only, 40 participants received Social Security Disability Income (SSDI) only, and 18 participants received both SSI and SSDI concurrently.

Each participant received a pre- and posttest to determine their level of knowledge and intentions before benefits counseling and after receiving the service. The pretest was composed of two parts: self-reported customer information (e.g., current benefits, work status, work-related questions) and pre-knowledge about the work incentives (three Likert scales with Don't know, Know somewhat, and Know a lot).

Three different posttests were created according to the type of SSA benefits (i.e., SSI only, SSDI only, and both SSI \& SSDI). The posttest consisted of three sections: knowledge about the SSA rules related to their benefit (True/ False), level of understanding about the work incentives (three Likert scales with Not at all, Somewhat, and A lot), and behavioral intention to use the work incentives in the future (Yes, No, and Maybe). Note that the number of questions was different from the type of SSA benefits; for example, there were five knowledge questions for SSI only and SSDI only, but six knowledge questions for both SSI \& SSDI posttests.

Prior to data collection, a series of staff training in terms 
of administration of the pre- and posttests was provided. The data were collected and analyzed to determine the effect of benefits counseling on participant overall knowledge about Social Security work rules and work incentives and their intentions to use them.

\section{Results \\ Knowledge of Social Security Work Rules}

Overall, participants receiving SSI demonstrated a better general knowledge of Social Security rules related to work and earnings following receipt of benefits counseling services than those receiving SSDI only and/or dual beneficiaries. Three-quarters (75\%) of individuals receiving SSI only answered all five questions correctly, $12.5 \%$ answered four questions correctly, $8.3 \%$ answered three correctly, while only one participant answered one question correctly. Comparatively, $66.7 \%$ of SSDI participants answered five questions correctly, $20.5 \%$ answered four questions, $10.3 \%$ answered three questions correctly, and $2.6 \%$ answered two questions correctly. Of the individuals who received both SSI and SSDI, 55.6\% of participants answered all six questions correctly, $11.1 \%$ answered five questions correctly, $22.2 \%$ answered four correctly and $11.1 \%$ of participants answered three questions correctly.

The average sum scores for each benefit group are as follows: 4.54 out of five questions for those with SSI only (reflecting $90.8 \%$ correct); 4.51 out of five for those with SSDI only (reflecting $90.2 \%$ correct); and 5.11 out of six for those with both SSI and SSDI (reflecting $85.2 \%$ correct). As indicated, participants showed a high level of immediate knowledge gain in all three groups.

\section{Knowledge of Work Incentives}

Work incentive knowledge increased in nearly all areas following receipt of benefits counseling, with the greatest gains observed with Expedited Reinstatement (66\%), Freedom to Work (58\%), and Impairment Related Work Expenses (IRWE). Participants reported a $23 \%$ decrease in knowledge regarding the Plan to Achieve Self-Support (PASS) incentive, and a $4 \%$ decrease in knowledge around Subsidy Housing (Section 8). Following receipt of benefits counseling, $84 \%$ of all recipients reported knowing $A$ lot or Somewhat about Ticket to Work, and 5\% reported no knowledge at all. It is noted that a higher proportion of participants knew about the Plan to Achieve Self-Support (PASS), Ticket to Work, food assistance program, and subsidized housing.

Note that all work incentives and support programs are not available for all participants. For example, Trial Work Period is designed to provide SSDI beneficiaries to test their ability to work for at least nine months without losing the case benefits. The MiCap program provides an opportunity for adult SSI recipients residing in Michigan to access food benefits. Table 1 presents the valid total numbers responded at pre- and posttest, regardless of the benefit types.

\section{Intent to Use Work Incentives}

The study also examined whether participants completing the $\mathrm{BC}$ services indicated any behavioral intention to use each work incentive/support program in the future. Only those who indicated that they understood (somewhat or a lot) a work incentive/support program at posttest were included for the computation. The work incentives participants reported the highest intent in using were the Ticket to Work (63\%), Expedited Reinstatement (48\%), Freedom to Work (45\%), and the Trial Work Period (41\%). The Freedom to Work incentive provides access to health-insurance through the state's Medicaid program. The three least likely used incentives include MiCap (7\%), PASS (6\%), and Unincurred Business Expenses (4\%).

\section{Recommendations and Implications for Practice}

This study found that participant knowledge of both Social Security work rules and work incentives increased overall following receipt of benefits counseling services. Having this knowledge will support and guide VR consumers in making informed decisions about work and earnings as they progress toward their employment goals. Although this was a short-term study focused primarily on measuring knowledge gain, a longer-term study is recommended to examine work intentions and employment outcomes for recipients and beneficiaries who received benefits counseling. The results of the evaluation will be used to improve service delivery to VR customers residing in Michigan who receive Social Security benefits. Based on findings from this study, the following recommendations are offered:

- Although there was collaboration at the beginning of the project, the vendor requested changes to the survey midway through the study, resulting in some data being invalid. It is recommended to not allow changes to test instruments once data collection has begun.

- Ensure a standard method of data collection to enhance validity.

- Given that Benefits Counseling services can improve customer knowledge of incentives and work rules, expanding use of this service is recommended.

- Even with increased general knowledge of work incentives, most customers intend to use incentives selectively (e.g., Ticket to Work, Expedited Reinstatement, and Trial Work Period).

\section{Author Note}

The contents of this paper were developed under a cooperative agreement with the U.S. Department of Education, Technical Assistance Center for Vocational Rehabilitation Agency Program Evaluation and Quality Assurance (PEQA-TAC) (Grant Award Number: H263B150004). However, the contents and views expressed in this publication do not necessarily represent the positions or policies of the U.S. Department of Education, and you should not assume endorsement by the Federal government. 
Table 1. Participant Knowledge of Work Incentives at Pre- and Posttest

\begin{tabular}{|c|c|c|c|}
\hline Work incentives & $\begin{array}{l}\text { Pretest (Know somewhat or } \\
\text { a lot) }\end{array}$ & $\begin{array}{l}\text { Posttest (Know somewhat } \\
\text { or a lot) }\end{array}$ & $\begin{array}{l}\text { Knowledge } \\
\text { change }\end{array}$ \\
\hline Ticket to Work & $43 \%$ & $84 \%$ & $41 \%$ \\
\hline Expedited Reinstatement & $10 \%$ & $76 \%$ & $66 \%$ \\
\hline Freedom to Work & $18 \%$ & $76 \%$ & $58 \%$ \\
\hline Trial Work Period & $5 \%$ & $46 \%$ & $41 \%$ \\
\hline Medicare Savings Program & $13 \%$ & $53 \%$ & $40 \%$ \\
\hline Food Assistance Program (SNAP) & $39 \%$ & $42 \%$ & $3 \%$ \\
\hline $\begin{array}{l}\text { Continuing Healthcare Coverage } \\
\text { [Section 1619(a)(b)] }\end{array}$ & $10 \%$ & $40 \%$ & $30 \%$ \\
\hline IRWE & $13 \%$ & $68 \%$ & $55 \%$ \\
\hline Extended Period of Eligibility & $13 \%$ & $41 \%$ & $28 \%$ \\
\hline $\begin{array}{l}\text { Reinstating Eligibility without a New } \\
\text { Application }\end{array}$ & $5 \%$ & $33 \%$ & $28 \%$ \\
\hline Earned Income Exclusion & $6 \%$ & $32 \%$ & $26 \%$ \\
\hline Unsuccessful Work Attempts & $3 \%$ & $25 \%$ & $22 \%$ \\
\hline Subsidy and Special Conditions & $3 \%$ & $25 \%$ & $22 \%$ \\
\hline Subsidy Housing (Section 8) & $22 \%$ & $18 \%$ & $-4 \%$ \\
\hline Section 301 & $4 \%$ & $26 \%$ & $22 \%$ \\
\hline Student Earned Income Exclusion & $6 \%$ & $13 \%$ & $7 \%$ \\
\hline $\begin{array}{l}\text { Michigan Combined Application Project } \\
\text { (Mi CAP) }\end{array}$ & $4 \%$ & $33 \%$ & $29 \%$ \\
\hline Plan to Achieve Self-Support (PASS) & $46 \%$ & $23 \%$ & $-23 \%$ \\
\hline Unincurred Business Expenses & $1 \%$ & $22 \%$ & $21 \%$ \\
\hline
\end{tabular}

Table 2. Participant Intent to Use Work Incentives

\begin{tabular}{|c|c|c|c|c|c|c|}
\hline \multirow[t]{2}{*}{ Work Incentives } & \multicolumn{2}{|c|}{ Will Use } & \multicolumn{2}{|c|}{ Will Not Use } & \multicolumn{2}{|c|}{ Might Use } \\
\hline & $\mathrm{n}$ & $\%$ & $\mathrm{n}$ & $\%$ & $\mathrm{n}$ & $\%$ \\
\hline IRWE & 25 & $30 \%$ & 14 & $17 \%$ & 17 & $21 \%$ \\
\hline Expedited Reinstatement & 39 & $48 \%$ & 6 & $7 \%$ & 12 & $15 \%$ \\
\hline Ticket to Work & 52 & $63 \%$ & 2 & $2 \%$ & 4 & $5 \%$ \\
\hline Plan to Achieve Self-Support (PASS) & 5 & $6 \%$ & 6 & $7 \%$ & 5 & $6 \%$ \\
\hline Freedom to Work & 37 & $45 \%$ & 3 & $4 \%$ & 11 & $13 \%$ \\
\hline Section 301 & 9 & $11 \%$ & 8 & $10 \%$ & 5 & $6 \%$ \\
\hline Earned Income Exclusion & 18 & $22 \%$ & 3 & $4 \%$ & 4 & $5 \%$ \\
\hline Student Earned Income Exclusion & 8 & $10 \%$ & 2 & $2 \%$ & 1 & $1 \%$ \\
\hline Trial Work Period & 34 & $41 \%$ & 4 & $5 \%$ & 4 & $5 \%$ \\
\hline Extended Period of Eligibility & 22 & $27 \%$ & 3 & $4 \%$ & 5 & $6 \%$ \\
\hline Reinstating Eligibility without a New Application & 21 & $26 \%$ & 2 & $2 \%$ & 2 & $2 \%$ \\
\hline Medicare Savings Program & 30 & $37 \%$ & 3 & $4 \%$ & 3 & $4 \%$ \\
\hline Continuing Healthcare Coverage [Section 1619(a)(b)] & 27 & $33 \%$ & 3 & $4 \%$ & 0 & $0 \%$ \\
\hline Unsuccessful Work Attempts & 12 & $15 \%$ & 3 & $4 \%$ & 2 & $2 \%$ \\
\hline Food Assistance Program (SNAP) & 29 & $35 \%$ & 7 & $9 \%$ & 1 & $1 \%$ \\
\hline Subsidy and Special Conditions & 10 & $12 \%$ & 6 & $7 \%$ & 4 & $5 \%$ \\
\hline Unincurred Business Expenses & 3 & $4 \%$ & 4 & $5 \%$ & 5 & $6 \%$ \\
\hline Subsidy Housing (Section 8) & 10 & $12 \%$ & 5 & $6 \%$ & 3 & $4 \%$ \\
\hline Michigan Combined Application Project (Mi CAP) & 6 & $7 \%$ & 4 & $5 \%$ & 0 & $0 \%$ \\
\hline
\end{tabular}




\section{References}

Hartman, E. C., Anderson, C. A., Chan, J. Y., Fried, J. H., \& Lui, J. W. (2015). An exploration of work incentive benefits specialists' experiences. Journal of Applied Rehabilitation Counseling, 46(3), 25-34. https://doi.or $\mathrm{g} / 10.1891 / 0047-2220.46 .3 .25$

Kregel, J. (2012). Work incentives planning and assistance program: Current program results document the program's ability to improve employment outcomes, reduce dependence on benefits, and generate cost savings for SSA. Journal of Vocational Rehabilitation, 36(1), 3-12. https://doi.org/ 10.3233/JVR-2012-0577

Mann, D., Mamun, A., \& Hemmeter, J. (2015). Employment, earnings, and primary impairments among beneficiaries of social security disability programs. Social Security Bulletin, 75(2), 19-40. http s://ssrn.com/abstract $=2604131$
Schlegelmilch, A., Roskowski, M., Anderson, C., Hartman, E., \& Decker-Maurer, H. (2019). The impact of work incentives benefits counseling on employment outcomes of transition-age youth receiving Supplemental Security Income (SSI) benefits. Journal of Vocational Rehabilitation, 51(2), 127-136. https://doi.org/10.3233/JVR-191032

Wilhelm, S., \& McCormick, S. (2013). The impact of a written benefits analysis by Utah benefit counseling/ WIPA program on vocational rehabilitation outcomes. Journal of Vocational Rehabilitation, 39(3), 219-228. ht tps://doi.org/10.3233/JVR-130656 